\title{
Sobre a Geografía del Perú de Javier Pulgar Vidal
}

Da região como categoría da prática à regionalização normativa

On Geografía del Perú by Javier Pulgar Vidal: from region as a category of practice to a normative regionalization

Sobre la Geografía del Perú de Javier Pulgar Vidal: de la región como una categoría practica à la regionalización normativa

Sur la Geografía del Perú de Javier Pulgar Vidal: de la région comme catégorie pratique à la régionalisation normative

\section{Rogério Haesbaert}

\section{(2) OpenEdition}

Journals

Edição electrónica

URL: https://journals.openedition.org/terrabrasilis/952

DOI: 10.4000/terrabrasilis.952

ISSN: 2316-7793

Editora

Rede Brasileira de História da Geografia e Geografia Histórica

Refêrencia eletrónica

Rogério Haesbaert, «Sobre a Geografía del Perú de Javier Pulgar Vidal», Terra Brasilis [Online], 3 | 2014, posto online no dia 26 agosto 2014, consultado o 05 dezembro 2022. URL: http://

journals.openedition.org/terrabrasilis/952 ; DOI: https://doi.org/10.4000/terrabrasilis.952

Este documento foi criado de forma automática no dia 5 dezembro 2022.

All rights reserved 


\section{Sobre a Geografía del Perú de Javier Pulgar Vidal}

Da região como categoría da prática à regionalização normativa

On Geografía del Perú by Javier Pulgar Vidal: from region as a category of practice to a normative regionalization

Sobre la Geografía del Perú de Javier Pulgar Vidal: de la región como una categoría practica à la regionalización normativa

Sur la Geografía del Perú de Javier Pulgar Vidal: de la région comme catégorie pratique à la régionalisation normative

\section{Rogério Haesbaert}

\section{NOTA DO EDITOR}

Com vistas a proporcionar ao leitor brasileiro um melhor conhecimento das idéias de Javier Pulgar a partir de suas formulações originais, oferecemos um fragmento da obra Geografía del Perú na seção "Clássicos e textos de referência” do presente número, acompanhado de um mapa e de um bloco diagrama sobre as oito regiões naturais do Peru.

(...) caminando por el campo nunca hablábamos con la gente culta que vivía en las ciudades, sino que íbamos hablar con los campesinos, con los chacareros, con la gente que ha guardado sabidurías tradicionales que venían desde muchos milenios.

(...) ciertamente he aprendido mucho de los comuneros porque la ciencia de ellos es todavía infinita y muy poco explorada. Javier Pulgar Vidal ${ }^{1}$ 
1 Javier María Pulgar Vidal (1911-2003) é um dos mais conhecidos geógrafos peruanos e provavelmente um dos geógrafos latino-americanos de maior inserção e influência institucional, já que foi reitor, secretário, ministro, embaixador e assessor de empresas, e fundou diversas universidades no Peru e também na Colômbia, onde, exilado, residiu durante dez anos, retornando muitos anos depois como embaixador. Não o conhecia até receber o convite dos editores de Terra Brasilis para este artigo e tive uma grata surpresa ao perceber sua trajetória e ler esta que foi uma de suas obras mais importantes, Geografía del Perú, em sua $9^{a}$ edição à que tive acesso, publicada em 1987. Como Milton Santos, no Brasil, era formado em Direito, mas muito cedo passou a exercer o magistério em Geografia, tendo sido auxiliar de cátedra ainda na graduação e também se interessava muito por Botânica e Arqueologia - fundamental que foi para a descoberta das ruínas da famosa huaca - lugar sagrado - de Kotosh (perto de sua cidade, Huánuco).

2 José Betancourt Rivera, diretor de Estudios y Análisis de Política Exterior do Ministério de Relações Exteriores do Peru, e que trabalhou com Javier Pulgar ${ }^{2}$ quando este foi embaixador na Colômbia, afirmou que ele foi responsável pela modernização e elaboração de um novo paradigma para a geografia peruana. Em suas palavras:

Los conceptos innovadores sobre los pisos ecológicos y la nueva ordenación territorial fueron presentados en su libro "Las 8 regiones naturales del Perú", obra que en su momento de publicación representó un cambio paradigmático en el estudio de la Geografía del Perú. El concepto de desarrollo transversal asociado a un nuevo ordenamiento territorial con fines económicos es evidentemente un aporte del sabio Pulgar Vidal (La Primera, 2013). ${ }^{3}$

3 Las 8 regiones naturales del Perú foi seu trabalho mais famoso, representando um questionamento da regionalização euro-hispanocêntrica até então dominante. Essa tese foi apresentada durante a Terceira Assembleia Geral do Instituto Panamericano de Geografia e História, realizada em Lima em 1940. Ainda que seu caráter precursor, em termos dos "pisos ecológicos" ou das "regiões transversais", possa ser questionado, ${ }^{4}$ não há dúvida que suas "oito regiões", identificadas a partir da "síntese" homem-meio e da nomenclatura reconhecida pelos próprios povos originários foi uma grande contribuição à geografia peruana.

4 A obra Geografía del Perú, aqui analisada, demonstra num mesmo trabalho a ampla preocupação do autor, envolvido com todas as dimensões da questão regional. Já na apresentação ("En torno a la obra"), Pulgar deixa clara sua afinidade com a região e os processos de regionalização vinculados à abordagem que enfatiza o que propomos denominar "categorias da prática", no sentido de concepções utilizadas no cotidiano pela "sabedoria popular" ou do senso comum da maioria da população, em suas próprias práticas de auto-atribuição identitária. Daí a importância dada à toponímia ("oronímia", "hidronímia"...): desvendar o significado dos nomes dos lugares seria capaz de revelar o conhecimento prático de seus habitantes. Ao mesmo tempo, ele reconhece a função analítica da categoria região e dos processos de regionalização ao discutir, na segunda parte do livro, "os diversos critérios de divisão do território" peruano, pela "aplicação de distintos pontos de vista e com finalidades imediatas diferentes" (Pulgar, 1987, p. 6).

5 Finalmente, o autor cobre o amplo espectro do debate regional através de uma derivação desses usos da região como categoria analítica e da prática, agora ressaltando sua aplicação nas dinâmicas de regionalização em termos políticos, de planejamento. 
Propusemos denominar essa abordagem como o trabalhar da região a partir de seu caráter de categoria normativa (Haesbaert, 2010), pela preocupação maior com "o que deve(ria) ser" a região (uma espécie de "região-plano"), mais do que com alguma definição do que "é" a região (de algum modo, a região como "fato"). Assim, aparecem, na terceira e quarta partes de Geografía del Perú, a proposta de uma "regionalização transversal", apresentada à Comissão Nacional de Regionalização, e um projeto de desenvolvimento através de uma microrregionalização administrativa.

Essas três dimensões é que nos servirão de base para a estruturação deste artigo: a perspectiva da região como categoria ou instrumento de análise, envolvida com os instrumentos e métodos de regionalização do geógrafo pesquisador, a região como categoria da prática, tal como concebida e vivida no senso comum e na prática cotidiana dos grupos sociais (a regionalização como ação incorporada na própria prática efetiva, vivida), e a região como categoria normativa, através da regionalização político-pragmática do geógrafo (ou do técnico-político) planejador.

\section{O geógrafo Pulgar Vidal entre o objetivo e o subjetivo: da região analítica "natural" à região "toponímica" vivida}

7 Pode-se afirmar que Javier Pulgar procurava não seccionar ou não dicotomizar o universo analítico do intelectual, formulador de conceitos e teorias "objetivos", e o universo vivido, mais subjetivo, daqueles que efetivamente construíam o espaço regional. Ao mesmo tempo em que se preocupava explicitamente com a "correção" e o rigor acadêmico, nutria um profundo respeito e consideração para com a sabedoria popular, como fica evidente nas citações que abrem este artigo. Além disso, sua própria análise, muitas vezes, era permeada por sua sensibilidade pessoal, a ponto de realizar ricas e mesmo poéticas descrições da paisagem.

8 Em termos analítico-conceituais, é interessante como, mesmo começando sua investigação a partir de uma concepção que ele denomina de região natural, esta vai além da simples "natureza natural", pois inclui o homem como, em suas palavras, seu "mais ativo agente modificador". Assim, afirma em sua introdução:

Consideramos que região natural é uma área contínua ou descontínua na qual são comuns ou similares o maior número de fatores do meio ambiente natural; e que, dentro de tais fatores, o homem joga papel principal ["principalísimo"] como o mais ativo agente modificador da natureza. (1987:11).

Afirma que no Peru é muito raro, exceto em alguns "vazios do ecúmeno", não haver intervenções expressivas do homem. A riqueza da diversidade geográfica é outro ponto que, de saída, ele enfatiza em sua caracterização do espaço peruano, pois "o meio ambiente natural peruano contém quase todas as regiões naturais do planeta", das florestas equatoriais amazônicas ao gelo eterno "polar" das altas montanhas.

Sua argumentação em favor de uma regionalização através de regiões-síntese e relativamente uniformes, em termos tradicionais, fica evidente quando defende "a consideração analítica de todos os fatores do meio ambiente natural" e uma "sistematização científica com base na comunidade [no caráter comum] e homogeneidade de todos ou da maioria desses fatores" (p. 12). Não há dúvida, entretanto, que um dos fatores fundamentais é a diferença de altitude, que implica 
profundas mudanças climato-botânicas. Seu mapa das oito regiões naturais traz claramente na própria legenda uma faixa altimétrica para cada uma das respectivas regiões.

11 Importante é que, mesmo baseando-se ainda num conceito de região natural (que, em outros momentos, ele denomina também de "pisos ecológicos" [p. 207, 209 e 210] ou mesmo de "geossistemas" [p. 209 e 210] ou, simplesmente, "sistemas" [p. 210]), inclui como elemento da natureza o homem, pois os "fatores básicos" a que se refere são identificados como "clima, relevo, solo, subsolo, águas subterrâneas, águas superficiais, mar, flora, fauna, grupos humanos, latitude e longitude" [grifo nosso] (numa articulação entre domínios materiais e localização em termos mais abstratos).

Essa região-síntese revela uma combinação "harmoniosa" e histórica "com a obra, a adaptação e as modificações que o homem realizou e realiza no território peruano". (p. 12) Em sua proposta de regionalização as oito regiões do Peru são apresentadas ao mesmo tempo como "realidades, problemas, possibilidades e soluções" (p. 13), deixando clara sua preocupação também com o planejamento regional, a regionalização potencializando soluções para os dilemas do país, como enfatizaremos na segunda parte deste artigo.

13 Um ponto muito relevante que gostaríamos de destacar é sua apresentação das oito regiões naturais (desde sua famosa tese dos anos 1930-40) a partir do reconhecimento de sua identificação pelos povos antigos e camponeses ("seus atuais herdeiros detentores milenários desta terra" [p. 12]), que irá depois confrontar "cientificamente com a realidade geográfica". Para Pulgar Vidal, a rapidez da conquista militar espanhola durante o processo de colonização não teria lhes permitido assimilar os conhecimentos dos povos indígenas. Assim, os colonizadores acabaram impondo denominações geográficas utilizadas na Península Ibérica, surgindo daí a clássica nomenclatura das três grandes regiões: "Llanos" (planícies) ou "Costa" para as áreas baixas e onduladas próximas ao Oceano Pacífico, "Sierras" ou simplesmente "Sierra" para as montanhas andinas e "Montaña" para a área oriental baixa e florestal da bacia Amazônica. Além dessa caracterização geográfica macro os espanhóis também modificaram denominações de animais, plantas e locais (que recebiam o nome de santos do dia em que ali chegaram). Assim, "os espanhóis acomodaram a geografia, a botânica, a zoologia e a toponímia, entre outras ciências, à sua própria cultura" (1987:13). ${ }^{6}$

14 A ideia da regionalização de um Peru dividido em apenas três regiões, como propagado pelos colonizadores, era (e é) totalmente ignorada pelo saber popular, o "saber geográfico indígena" tal como defendido por Pulgar. Dessa forma, quando indagado sobre a região em que vivem, os camponeses respondem que moram "na Yunga, na Quechua, na Suni etc.” Daí resulta a identificação das oito regiões como:

- Chala (ou Costa), região junto ao mar na encosta ocidental dos Andes;

- Yunga, área quente dos vales e desfiladeiros ("quebradas") que sobem aos Andes em suas duas vertentes, oriental e ocidental (mesma nomenclatura que pode ser encontrada até o norte da Argentina, na região de Tucumán e Salta);

- Quechua, terras temperadas que também se estendem nos dois declives andinos;

- Suni ou Jalca, correspondente às "terras frias";

- Puna, região dos altiplanos e penhascos ("riscos") muito frios;

-Janca, picos nevados ou "regiões brancas";

- Rupa-Rupa (ou Selva Alta), parte de morros e vales florestados na vertente oriental andina; 
- Omagua (Selva Baixa ou Amazônia), grande planície oriental amazônica. espaço vivido que o autor passou a enfatizar o estudo da toponímia e da etimologia por seu "imenso valor documental" para o conhecimento geográfico (p. 17). ${ }^{7} \mathrm{Em} 1947$ ele foi mesmo o responsável pela criação do Fondo Toponímico del Perú. ${ }^{8}$ Os antigos habitantes do país somente criavam uma denominação geográfica depois de um minucioso levantamento das características específicas de cada local, nome que, portanto, representava claramente uma síntese dessas características. E mesmos nomes podiam ser aplicados a espaços separados, mas com características semelhantes, o que manifesta, a partir do próprio espaço vivido, a possibilidade de identificação de regiões descontínuas. $O$ autor leva em conta até mesmo os tipos climáticos (também em número de oito) tal como identificados pelos povos indígenas.

Pulgar Vidal propõe a noção de "produtos limite" para muitos produtos agrícolas que podem ser considerados restritos ou específicos de determinadas regiões, levando em conta suas características físicas, especialmente clima/altitude e solo. A constante e diferenciada ação humana também é ressaltada como fundamental na caracterização de cada uma das oito regiões peruanas. Finalmente, ele ressalta que as oito regiões não se referem a toda a extensão longitudinal do país, sendo melhor identificadas na sua porção mais central (de Lima à Amazônia) e que não há limites bruscos entre as regiões, pois "a diversidade de zonas não só se deve à maior ou menor altitude, mas depende também da orientação do lugar, da sombra dos morros, dos ventos dominantes e da vertente, ocidental ou oriental, em que esteja situada", resultando numa interpenetração de regiões (p. 23).

Após sua Introdução, de caráter mais metodológico, sobre seu conceito de região e seu método de regionalização, Javier Pulgar passa a descrever cada uma das oito regiões, utilizando-se para isso de um quadro sistemático praticamente padronizado. Fiel à importância que dá à toponímia, inicia o estudo de cada região analisando sua nomenclatura. A seguir analisa sua localização e faixa de altitude, antes de passar ao estudo dos elementos físicos: relevo, clima, flora e vegetação, "produtos (agrícolas) limite" e fauna. Depois, numa perspectiva histórico-cultural, analisa "a obra do homem antigo" e a "obra do homem atual". Finalmente, onde se encontram algumas de suas descrições mais ricas, que demonstram também seu pendor literário, trabalha o item "paisagem". É curioso como, mesmo sem nenhuma discussão conceitual sobre paisagem, reserva para este item uma abordagem que não compreende a paisagem simplesmente como morfologia, como nas leituras mais tradicionais, mas também em sua dimensão mais subjetiva.

18 Para uma pequena mostra da riqueza dessa apresentação das paisagens, reproduzimos abaixo uma passagem sobre a Puna, no original em espanhol, não só pela dificuldade de tradução mas, sobretudo, para não perder a sonoridade poética do texto:

Puna, región grácilmente vestida con champas verdes o amarillentas: decorada por los rios nacientes que describen juguetones y diminutos meandros o que salen de la madre para dormir una siesta sobre el mullido lecho de las plantas acuáticas, convirtiéndose en fugaces espejuelos. Lagunas de diamantes guardados en arcas de piedra. Ojos de água viva. Conchas cuyos fondos de ópalo, cobalto y esmeralda, reflejan el celeste y el azul infinitos del cielo en los dias tranquilos, el gris caliginoso de las lóbregas tormentas, el broche rutilante del relâmpago, la gélida imagen de la luna y el guiñar tembloroso de los domos estrellados. (...) Inmensa tierra de horizontes mayores que los del mar y de la selva. En sus pampas no hace falta la

Terra Brasilis, 3 | 2014 
energia y realmente no es triste; tiene si, um lánguido sueño, como de recién nacido y toda la belleza delicada de los seres tiernos (pp. 109-110).

O grande geógrafo, aqui, extrapola da região vivida pelos indígenas e camponeses para a sua própria vivência da região, numa descrição poética que não suprime a análise, mas a enriquece com a densa sensibilidade subjetiva do "investigador". Pulgar Vidal nos faz assim reencontrar o grande geógrafo francês Eric Dardel, quando afirma:

A linguagem do geógrafo se torna sem esforço aquela do poeta. Linguagem direta, transparente, que "fala" sem esforço à imaginação, sem dúvida muito melhor que o discurso "objetivo" do intelectual, pois ela transcreve fielmente a "escritura" traçada sobre o solo (p. 3). o rigor da ciência nada perde ao confiar sua mensagem a um observador que sabe admirar, escolher a imagem justa, luminosa (...). Uma visão puramente científica do mundo poderia muito bem designar, como nos indica Paul Ricoeur, uma tentativa de abdicar, "uma vertigem de objetividade", um "refúgio quando estou cansado de desejar e que a audácia e o perigo de ser livre me pesam" (Dardel, 1990[1952]:126).

Na segunda parte do livro, intitulada "Otros criterios sobre división y sub-división del territorio peruano", é onde aparece de forma mais explícita a região em sua perspectiva de instrumento de análise, e onde o reconhecimento de múltiplas regionalizações implica concebê-las como "setores, seções, zonas ou áreas" cuja divisão depende dos critérios adotados pelo pesquisador. Ele elenca aí 13 critérios, desde regiões elementares, definidas por um único critério físico-natural, até regiões definidas a partir de um sujeito específico - os antigos povoadores que vieram do Panamá e Colômbia, os colonizadores espanhóis ou, hoje, os "aviadores" e sua visão do alto. É curioso como apenas dois desses critérios focalizam o homem, visto ou em sua "adaptação" ao meio ou pelo "critério político" para fins de administração pública. Mais surpreendente ainda é verificar que nenhum desses critérios explicita a questão urbana, tão relevante em várias propostas de regionalização desde o ínicio do século XX, com a concepção de nodalidade formulada por Mackinder e desdobrada por Vidal de la Blache (a propósito, ver Vidal de la Blache, 2012a[1910] e 2012b[1911]).

O $14^{\circ}$ critério envolve sua própria proposta, a das oito regiões "integrais" do Peru, ao lado das do geógrafo alemão Carl Troll e do francês Olivier Dollfus. Fica evidente, aqui, que ele defende suas "regiões integrais" ou "complexas" em relação às demais "regiões elementares", definidas basicamente por um único critério. O último critério é o proposto por aqueles "que consideram que a divisão de um território em regiões naturais deve ser feito com relação ao caráter comum ["en atención a la comunidad"] de todos ou da maioria dos fatores do meio ambiente natural" (p. 199), o que, obviamente, como já vimos, inclui a ocupação humana e sua "sabedoria geográfica tradicional". Nas considerações gerais iniciais do capítulo ele traduz com outras palavras este critério, dando muito mais destaque à imbricação homem-meio, pois o lê como o critério dos que julgam que, "para dividir o território, é necessário a análise integral de todos os fatores do meio, incluindo o grupo humano" ou, em outras palavras:

(...) a análise cabal do território só é possível mediante a consideração integrada de todos os fatores do meio ambiente natural, combinados de maneira consciente e em processo histórico e atual com a obra, a adaptação e as modificações que o homem realizou e realiza no território peruano (p. 179-180). 


\section{O geógrafo Pulgar Vidal político-planejador e a regionalização normativa}

Javier Pulgar Vidal, muito além de um intelectual no sentido do trabalho acadêmico restrito ao ambiente universitário, foi uma personalidade política de seu país, profundamente engajado na aplicação de seus conhecimentos geográficos através do aparato estatal, especialmente a partir de sua filiação à centro-esquerdista APRA (Aliança Popular Revolucionária Americana). Sua atuação política, que para alguns começou de maneira fortuita, convidado para a Secretaria de Fomento quando ensinava em Huánuco, incluiu postos como o de secretário do Ministério de Fomento, deputado no Congresso Nacional, primeiro reitor da Universidade Comunal do Centro do Peru e embaixador na Colômbia. Independente do amplo reconhecimento de seu prestígio intelectual, sua participação junto à APRA foi por vezes polêmica, como no debate sobre a fundação da Universidade Comunal do Centro, em que os interesses partidários apristas acabaram se sobrepondo aos dos estudantes e comuneros. ${ }^{9}$

Logo no início de sua carreira e a partir de contato com o vice-presidente americano Henry Wallace quando de sua visita ao Peru, em 1943, conseguiu uma bolsa de estudos de oito meses nos Estados Unidos, quando trabalhou na National Planning Association junto com intelectuais como C. Jones, P. James e R. Platt. Segundo artigo de Córdova e Bernex $(\mathrm{s} / \mathrm{d})$, com base em depoimento do próprio Pulgar, foi através desse estágio que ele "aperfeiçoou sua técnicas de investigação geográfica a partir da análise integral de áreas". Por ocasião de sua estada nos Estados Unidos teve contato e realizou intercâmbio com o geógrafo brasileiro Jorge Zarur, membro do então Conselho Nacional de Geografia e conhecido por seu estudo sobre o rio São Francisco (Zarur, 1946).

24 Sua participação em atividades junto a órgãos estatais de planejamento incluiu diversos outros trabalhos, destacando-se sua atuação junto a projetos de regionalização do Peru, fato que fica muito evidente na terceira e quarta partes do livro Geografía del Perú, aqui analisado. Pulgar Vidal apresenta aí aquela que, depois da definição das oito "regiões naturais", constitui sua mais divulgada contribuição aos estudos geográficos: a "regionalização transversal" do país. Segundo o próprio autor, essa regionalização foi proposta por ele em 1976 através de comunicação ao primeiro-ministro General Oscar Vargas Prieto. Depois, em 1978 e 1979, foi apresentada à Comissão de Regionalização da Assembleia Constituinte e várias outras instituições, incluindo a Associação Nacional de Clubes Departamentais do Peru.

É interessante ressaltar que o embrião dessa "regionalização transversal", como nos lembrou o geógrafo peruano Juan Manuel Delgado, já se encontra em Mariátegui, o grande socialista peruano, pelo menos em termos da relação entre Costa e Sierra. Segundo Mariátegui:

La sierra y la costa, geográfica y sociológicamente, son dos regiones; pero no pueden serlo política y administrativamente. Las distancias interandinas son mayores que las distancias entre la sierra y la costa. El movimiento espontáneo de la economía peruana trabaja por la comunicación transandina. Solicita la preferencia de las vías de penetración sobre las vías longitudinales. El desarrollo de los centros productores de la sierra depende de la salida al mar (p. 133). (...) La explotación de los recursos de la sierra y la montaña [Selva ou Amazônia] reclama vías de penetración, o sea vías que darán, a lo largo de la costa, diversas desembocaduras a nuestros productos. En la costa, el transporte marítimo no dejará 
sentir de inmediato ninguna necesidad de grandes vías longitudinales. Las vías longitudinales serán interandinas. $Y$ una ciudad costeña como Lima, no podrá ser la estación central de esta complicada red que, necesariamente, buscará las salidas más baratas y fáciles (Mariátegui, 1928:137). pela regionalização enquanto projeto de descentralização territorial, já tão enfatizada por Mariátegui, numa posição muito mais à esquerda, ${ }^{10}$ mas também estimulada pelos governos apristas e que culminou com as gestões de Alan García, um dos fundadores e principal liderança do atual Partido Aprista Peruano. García foi presidente do Peru por duas vezes (1985-1990 e 2006-2011) e é autor de pelo menos dois livros que revelam uma grande preocupação com a questão regional: La revolución regional (García, 1990) e Mi gobierno hizo la regionalización: Fujimori la destruyó en un año (1998).

É interessante como Pulgar Vidal inicia a Terceira Parte do livro (denominada "A regionalização transversal do Peru") fazendo alusão, também, ao caráter pedagógico da região, demonstrando sua preocupação com a forma pela qual as regiões eram trabalhadas pelos professores em sala de aula. ${ }^{11}$ À medida em que a região foi convertida em "objeto de estudo para o Ensino Secundário", "alguns professores incorreram em confusões que dificultam o aprendizado e desorientam os estudantes" (p. 207). Seu principal argumento para esclarecer a questão e, de modo simples, expor o principal argumento da regionalização transversal e sua combinação com as oito regiões naturais, é que:

(...) no Peru, assim como as riquezas e os recursos naturais são melhor aproveitáveis de leste a oeste ou ao revés, na direção dos paralelos, as regiões naturais se orientam de sul a norte, isto é, na direção dos meridianos. A combinação dos critérios utilizados e analisados no estudo das Oito Regiões Naturais existentes no território facilita a compreensão da abordagem da eventual Regionalização Transversal que foi aprovada em numerosos fóruns (...) (p. 207).

A divisão regional em regiões transversais tem um claro caráter prático-normativo, na medida em que prioriza o "melhor aproveitamento" dos recursos do país e leva em conta, também, a questão administrativa, a ponto de ter sido formulada com a pretensão de ser adotada em uma nova política de divisão político-administrativa do país. A ideia de transversalidade implica regionalizar o território peruano de tal forma que cada região, recortada do litoral do Pacífico até a Amazônia, corresponda a setores que reúnam características de todas as oito regiões naturais. Seu propósito, portanto, é:

(...) assegurar a cada futura região a possibilidade de dispor de toda classe de riquezas e recursos naturais que lhe permitam alcançar um desenvolvimento sustentável e conseguir a consequente abundância e folga. Dito de outra forma, cada região deve dispor das proteínas animais e vegetais do Oceano Pacífico, que é muito rico em espécies comestíveis, deve aproveitar todos os recursos mineiros, agrícolas, pecuários e as fontes de energia existentes na Costa e nas cadeias andinas; e, finalmente, deve utilizar, conservar e melhorar os recursos florestais, hidrobiológicos, agrícolas e pecuários das Selvas Alta e Baixa, bem como da Ceja de Selva (p. 208).

Trata-se de uma clara mudança de perspectiva, de uma regionalização "clássica", produto da relação homem-meio e "de baixo para cima", no reconhecimento enquanto regiões "vividas" por seus próprios habitantes, para uma regionalização geoeconômica, prescritiva, "de cima para baixo", ou melhor, que indique um caminho para uma nova geoeconomia do país, dentro de um discurso desenvolvimentista. Trata-se, portanto, de regiões marcadas mais pelo princípio da complementaridade que da homogeneidade $\mathrm{e}$ 
com claro caráter normativo com o objetivo, inclusive, de transformá-las em regiões político-administrativas, oficialmente instituídas. Como sua delimitação não obedece, obrigatoriamente, aos limites dos departamentos já existentes, essa regionalização implicaria uma substancial modificação territorial.

O autor demonstra sua preocupação com a descentralização político-administrativa, o "desenvolvimento sustentável" (por mais polêmica que seja a expressão) e, como em posturas contemporâneas de "biorregiões", uma espécie de região autossuficiente ou, pelo menos, que disponha da maior diversidade de recursos possível dentro da realidade geográfica peruana. A partir desse princípio de que cada região deveria dispor do maior número de recursos ele critica a própria divisão departamental do país, que não levou em conta "as fontes causais das riquezas e recursos dos povos" (p. 209).

Para a elaboração de sua regionalização transversal Pulgar Vidal discute cinco "fundamentos": o fundamento mais propriamente geográfico (com os "quatro elementos geográficos: o Mar Pacífico Peruano, o Semi-Llano [Semi-Planície] Costeiro, a Cadeia dos Andes e o Semi-Llano Amazônico), o fundamento ecológico (que surpreendentemente, aqui, ele identifica com os "pisos ecológicos" ou "geossistemas" e elenca suas oito regiões naturais), o fundamento pré-histórico e arqueológico (demonstrando a importância que concedia à Arqueologia, onde enfatiza a existência ancestral de um "intercâmbio transversal entre todos os geossistemas" [p. 211]) ${ }^{12} \mathrm{o}$ fundamento histórico propriamente dito e o "fundamento da história atual".

Vale destacar que o autor comenta os projetos já então encaminhados para uma nova regionalização administrativa do país, onde são defendidas "regiões administrativas" que busquem "a integração geoeconômica transversal" do país (p. 215, aludindo ao Anteprojeto de Decreto de Lei de Regionalização Administrativa publicado em 1975). É muito interessante perceber que, ao lado de sua preocupação com a urgência da operacionalização dessa proposta de regionalização (que inclui outra, a nível microrregional, comentada no último capítulo do livro), existe também o reconhecimento de seu empenho, especialmente através de publicações e conferências (inclusive junto à Assembleia Constituinte), de "criar uma consciência regionalista que adote o critério da transversalidade". Muito além de mero caráter analítico e/ou aplicado, trata-se igualmente da pretensão em fomentar uma nova "consciência regionalista" na forma de pensar (e viver) o espaço peruano.

\section{Considerações finais}

Concluindo, poderíamos propor que a Geografía del Perú de Javier Pulgar Vidal, profundamente marcada por influências da chamada Geografia Regional Clássica, de matriz francesa, deveria ser lida pelo viés crítico já tão enfatizado por geógrafos neopositivistas e marxistas, destacando aspectos como o peso excessivo da descrição e do mesmo receituário de método para a análise de todas as regiões, o menosprezo pelo papel das cidades $^{13}$ ou a ausência de um estudo dos conflitos e das contradições geoeconômicas impostas pelo sistema capitalista hegemônico (e que um autor como Mariátegui, muito tempo antes, já havia ressaltado). Optamos, porém, e isso deve ter ficado claro ao longo do texto, por uma outra vertente "crítica", aquela que, no lugar de destacar o que o autor "não fez" ou, no seu tempo, não permitiu fazer, privilegia, no interior mesmo do que ele "fez", o que ainda nos inspira ou, em outras palavras, o que nos permitiria (re)fazer, através de seu caráter de algum modo inovador. Assim, ao 
invés de enfatizarmos a falta, destacamos o que porventura existiria "a mais" em sua obra, o potencial que aporta para releituras, as possibilidades que (ainda) abre e os cruzamentos que permite no contexto da atual Geografia latino-americana.

Ao tratar a região tanto do ponto de vista dos próprios habitantes que "fazem" a região, numa espécie de ação concreta de "regionalizar", inclusive pela atribuição de toponímias regionais integradoras, quanto dos pesquisadores que a analisam a partir de múltiplos critérios de regionalização (embora escolhendo um deles como o mais adequado) e dos planejadores que invocam uma "região-devir" ou o futuro dos processos regionais, Pulgar Vidal pode ser considerado um "geógrafo regional pleno". E isso não apenas no sentido de cobrir todas as facetas com que a questão regional pode ser abordada, do prático-vivido ao analítico e ao normativo (sem falar em sua preocupação pedagógica). Sua obra também se caracteriza como uma abordagem do regional em sentido "pleno" porque defende uma visão efetivamente integradora para a análise regional, o que permite reavaliá-lo, hoje, à luz de conceitos como o de biorregião, ao proporem um resgate, em novas bases, da relação sociedade-natureza, fundamental para compreender as práticas "territoriais-regionais" de tantos grupos subalternos, notadamente os indígenas e comuneros, tão reconhecidos por Pulgar.

Suas vinculações profissionais multidisciplinares e seu apego ao trabalho de campo foram responsáveis por uma rica trajetória político-acadêmica, amplamente alinhada como os interesses políticos do aprismo peruano (e suas contradições). Mesmo atendose a uma "sabedoria geográfica tradicional" que era focada sobre as relações homemmeio, e tendo como objetivo proporcionar uma "visão completa" e um "conhecimento geográfico preciso e exato" do país, Pulgar nem por isso deixa de reconhecer o "dinamismo" no qual se inscreve a área da Geografia Regional e sua necessidade de "permanente revisão e atualização" (p. 6). o fato de ter finalizado Geografía del Perú já nos anos 1980 e mesmo assim ter dado prioridade a sua tese das oito regiões naturais do final dos anos 1930 (a primeira parte, que lhes diz respeito, ocupa mais de 2/3 do livro) prova a importância de releitura de suas proposições originais, associadas agora à tese mais pragmática das regiões transversais.

Ao mesmo tempo em que praticou uma Geografia Regional no seu melhor sentido clássico, com ênfase nas relações do homem com o meio físico-natural (e onde o homem, surpreendentemente, era encarado como um fator constituinte da própria natureza ou, de maneira mais elaborada, de um "geossistema"), esteve sempre atento à apropriação cultural efetuada pelo homem comum em seu espaço cotidiano, a ponto de valorizar, um pouco como um certo Vidal de la Blache e, mais tarde, Eric Dardel, a percepção e o conhecimento que os próprios habitantes, neste caso sobretudo camponeses (ou comuneros, como ele afirma), construíam em conjunto com seu entorno geográfico. Ao mesmo tempo, seus próprios princípios de regionalização, seja com propósitos de caráter mais analítico (como nas oito regiões naturais) ou normativo (como na regionalização transversal), advertem-nos para a importância de contextualizar nossas regionalizações de acordo com o espaço-tempo a que nos estamos referindo.

Esse reconhecimento e valorização da "sabedoria tradicional", como o autor denomina, adquire hoje uma enorme atualidade diante da releitura de nosso contexto geohistórico a partir do chamado pensamento pós ou descolonial, ao destacar uma perspectiva latino-americana (neste caso, também peruana) de construção do saber. 
Reler Pulgar Vidal em sua vinculação com outros pensadores da região, dentro e fora do Peru, pode inspirar, portanto, novas frentes de investigação.

\section{BIBLIOGRAFIA}

Córdova, H. e Bernex, N. s/d. O amauta Javier Pulgar. Disponível em: http://ciga.pucp.edu.pe/ index.php?option=com_content\&task=seccion_ciga\&sectionid=15\&id=499 (acessado em 24.08.2013)

Dardel, E. 1990 (1952) L'Homme et la Terre: nature de la réalité géographique. Paris: CTHS. (ed. brasileira: O Homem e a Terra: natureza da realidade geográfica. São Paulo: Perspectiva, 2011)

García, A. 1990. La revolución regional. Lima: Desa.

1998. Mi gobierno hizo la regionalización: Fujimori la destruyó en un año. Lima: Presente.

Haesbaert, R. 2010. Regional-Global: dilemas da região e da regionalização. Rio de Janeiro: Bertrand Brasil.

Mariátegui, J. C. 1928. Siete ensayos de interpretación de la realidad peruana. Lima. Disponível on-line: http://www.lahaine.org/amauta/b2-img/Mariategui\%20Siete\% 20Ensayos.pdf (acessado em out. 2013)

Paz Soldan, M. 1877. Diccionario Geográfico Estadístico del Perú. Lima: Imprenta del Estado Disponível on-line: https://ia700202.us.archive.org/12/items/ diccionariogeog01soldgoog/ diccionariogeog01soldgoog.pdf (acessado em out. 2013)

Pulgar Vidal, J. 1987. Geografía del Perú. Lima: Promoción Editorial Inca S.A. (PEISA)

Rose-Redwood, R.; Alderman, A. e Azaryahu, M. 2010. Geography of toponymic inscriptions: new directions in critical place-name studies. Progress in Human Geography 34(4).

Vidal de la Blache, P. 2012a(1910). As regiões francesas. In: Haesbaert, R.; Pereira, S. e Ribeiro, G. (org.) Vidal, Vidais: textos de Geografia Humana, Regional e Política. Rio de Janeiro: Bertrand Brasil. 2012b(1911). A relatividade das divisões regionais. In: Haesbaert, R.; Pereira, S. e Ribeiro, G. (org.) Vidal, Vidais: textos de Geografia Humana, Regional e Política. Rio de Janeiro: Bertrand Brasil. Zarur, J. 1946. A bacia do médio São Francisco. Rio de Janeiro: IBGE.

\section{NOTAS}

1. . Entrevista reproduzida no Youtube: http://peru21.pe/2012/03/05/reportuit/concytecdifunde-entrevista-al-amauta-javier-pulgar-vidal-2014546 (acessada em 24.08.2013)

2. Privilegiaremos aqui o primeiro sobrenome do autor, em coerência com a norma em língua espanhola.

3. Artigo "El legado de Javier Pulgar Vidal", publicado por ocasião dos 10 anos de falecimento do geógrafo no jornal La Primera de 19 de maio de 2013, e disponível on-line em http:// 
www.diariolaprimeraperu.com/online/especial/el-legado-de-javier-pulgar-vidal_138922.html (acessado em 23.08.2013).

4. Como revelou-me, em contato pessoal, o geógrafo peruano Juan Manuel Delgado, que pesquisa autores mais antigos como Mariano Paz Soldan (geógrafo e historiador peruano do século XIX) e José Carlos Mariátegui (comentado mais adiante).

5. É importante lembrar que "monte" em espanhol significa também bosque ou campo.

6. O próprio nome do país, Peru, foi uma imposição dos espanhóis: "Os povoadores do Tahuantinguyo nunca denominaram Peru a seu país. Foram os espanhóis que impuseram tal nome, criado pelos aborígenes de Darién e do Chocó [regiões ao norte entre os atuais Panamá e Colômbia]. E, passando os anos, a voz 'Peru' rodou o mundo como o nome de um país muito rico, suntuoso e opulento". (p. 214)

7. A propósito, ver a atualidade dos estudos toponímicos numa visão crítica da Geografia e mesmo com a proposição de uma "economia política" no estudo dos nomes dos lugares em RoseRedwood et al., 2010.

8. Segundo o geógrafo Juan Manuel Delgado ele teria se inspirado no Diccionario Geográfico Estadístico del Peru: la etimologia aymara y quéchua de las principales poblaciones, lagos, rios, cerros, etc. etc., do geógrafo e historiador Mariano Felipe Paz Soldan (1877), que em suas 1077 páginas traz a origem etimológica de várias denominações de lugares do Peru. Este dicionário encontra-se acessível em: https://archive.org/details/diccionariogeog01soldgoog

9. A princípio uma iniciativa dos "comuneros" a universidade foi criada como instituição privada (processo que envolvia Pulgar Vidal) e só mais tarde nacionalizada. Para uma crítica dos estudantes sobre o caso ver http://espanol.groups.yahoo.com/group/PERU_LIBRE/message/1933 (acessado em 9.10.2013)

10. Mariátegui é realmente precursor, também, no que se refere ao debate sobre o regionalismo peruano, em seu sentido político e econômico. Ele defende uma descentralização pautada num "novo regionalismo" não latifundiário e "gamonalista" (expressão peruana para um grupo e ideário conservador dominante), pautado na força do indígena e que vá além da discussão sobre descentralização, incorporando o debate sobre o "problema social”, em sentido amplo: “... comienza a bosquejarse un nuevo regionalismo [que] no es una mera protesta contra el régimen centralista. Es una expresión de la conciencia serrana y del sentimiento andino. Los nuevos regionalistas son, ante todo, indigenistas. No se les puede confundir con los anticentralistas de viejo tipo. (...) El problema primario, para estos regionalistas, es el problema del indio y de la tierra. (...) La autonomía municipal, el self government, la descentralización administrativa, no pueden ser regateados ni discutidos en sí mismos. Pero, desde los puntos de vista de una integral y radical renovación, tienen que ser considerados y apreciados en sus relaciones con el problema social" (Mariátegui, 1928:133).

11. Em nosso livro "Regional-Global" reconhecemos, em uma nota, a importante especificidade desse "caráter pedagógico" da região e da regionalização: "não podemos esquecer que, junto a esse caráter analítico da região, em sentido mais estrito, encontra-se também seu caráter pedagógico, voltado para o ensino, em que diferentes formas de recorte 'regional' são propostas de acordo com o contexto geo-histórico e ideológico em que se está situado", e onde "uma regionalização como 'representação didática', de caráter propositalmente analítico, pode ter profundas implicações em nossa leitura 'prática' (e ideológica) do mundo" (Haesbaert, 2010:185).

12. "Em resumo, podemos dizer que o homem mais remoto, talvez há dez mil anos atrás, mais ou menos, já conhecia o território, atravessava-o de leste a oeste e vice-versa, com maior facilidade que de sul a norte, ainda que a puna sempre tenha servido para deslocar-se longitudinalmente, podendo passar de um vale a outro em suas nascentes" (Pulgar Vidal, 1987:213).

13. A única referência mais explícita ao papel das grandes cidades aparece quando da definição, no Segundo (1982) e Terceiro (1984) Projetos de Regionalização Transversal, de uma "área metropolitana" no entorno de Lima (citada apenas em termo de localização, respectivamente, nas 
páginas 220 e 221 do livro Geografía del Perú), que subverte a ideia de transversalidade das demais regiões e provavelmente por isso é a única que não é tratada especificamente como "região", mas como "área".

\section{RESUMOS}

Javier María Pulgar Vidal é um dos mais conhecidos geógrafos peruanos e se tornou referência indispensável na compreensão da regionalização de seu país. Em uma de suas obras mais importantes, Geografía del Perú, o autor retoma a tese das "oito regiões", identificadas a partir da "síntese" homem-meio e da toponímia reconhecida pelos próprios povos originários, e discute também as "regiões transversais", propostas como modelo para uma nova política regional do país.

Javier Maria Pulgar is one of the most renowned geographers of Peru and is a key reference for understanding the regionalization of his country. In one of his most important works, "Geography of Peru," the author returns to his thesis of "eight regions," identified by the manenvironment synthesis and by the toponymy as recognized by native Peruvians. He also discusses the "transferal region" as a proposed model for new regional politics in Peru.

Javier María Pulgar Vidal es uno de los geógrafos más conocidos del Perú y se convirtió en una referencia indispensable para la comprensión de la regionalización de su país. En una de sus obras más importantes, la "Geografía del Perú", el autor retoma la tesis de las "ocho regiones" identificadas a partir de la "síntesis" hombre-medio y de la toponimia reconocida por los propios pueblos originarios. A su vez, analiza también las "regiones transversales", concebidas como modelo para una nueva política regional del país.

Javier María Pulgar Vidal est l'un des géographes les plus connus du Pérou et est devenu la référence incontournable pour la compréhension de la régionalisation de son pays. Dans une de ses œuvres les plus importantes, "Geografia del Perú », l'auteur reprend la thèse de «huit régions » identifiées à partir de la synthèse homme-milieu et de la toponomie reconnue par les peuples autochtones eux-mêmes, en faisant aussi la discussion des " régions trasnversales ", proposés comme un modèle pour une nouvelle politique régionale du pays.

\section{ÍNDICE}

Índice geográfico: Peru

Palavras-chave: Javier Pulgar Vidal, região, regionalização, Peru

Palabras claves: Javier Pulgar Vidal, región, regionalización, Perú

Índice cronológico: 1930-1998

Mots-clés: Javier Pulgar Vidal, région, régionalisation, Pérou

Keywords: Javier Pulgar Vidal, región, regionalization, Peru 


\section{AUTOR}

\section{ROGÉRIO HAESBAERT}

Professor do Departamento de Geografia da UFF; doutor em Geografia pela USP, com doutorado sanduíche pelo Instituto de Ciência Política de Paris; pós-doutor pela Open University (Milton Keynes, Inglaterra). 